\title{
Local Failure and Reliability Analysis of Horizontal Struts in Deep Excavation Based on Redundancy Theory
}

\author{
Jianhua LIU ${ }^{\mathrm{a}}$, Shaoming WU ${ }^{\mathrm{a}}$, Linfeng WANG ${ }^{\mathrm{b}, \mathrm{c}, 1}$ and Xiaohan ZHOU ${ }^{\mathrm{b}, \mathrm{c}}$ \\ ${ }^{a}$ Guangzhou Expressway Co. Ltd, Guangzhou 510290, P.R. China \\ ${ }^{\mathrm{b}}$ School of Civil Engineering, Chongqing University, Chongqing 400045, P.R. China \\ ${ }^{\mathrm{c}}$ Key Laboratory of New Technology for Construction of Cities in Mountain Area \\ (Chongqing University), Ministry of Education, Chongqing 400030, P.R. China
}

\begin{abstract}
The instability failure of many deep excavations supported by diaphragm walls (retaining piles) and horizontal struts is caused by the local failure of struts and the following large area chain effect. The lack of redundancy of struts is an important reason for the overall failure of supporting structures. In this paper, based on an actual excavation project, the numerical calculation model is established by Flac $^{3 \mathrm{D}} 5.0$, and the reliability of the supporting structure is analyzed based on the redundancy theory. The main conclusions are as follows: the redundancy of single support is large, and strut (6) (close to the middle of the excavation) is the most important. The redundancy is reduced due to continuous failure, and the redundancy is only 3.50 when strut (1) - (7) are all failed (half of the struts). The second row of the struts has the smallest redundancy, while the third row has the biggest redundancy.
\end{abstract}

Keywords. Redundancy theory, deep excavation, horizontal struts, local failure, reliability, numerical simulation

\section{Introduction}

Due to the advantages of large stiffness, strong resistance to deformation and no occupation of external space, diaphragm walls (support piles) + horizontal struts is more and more widely used in deep excavation. However, many excavation accidents showed that the local failure of the struts often leads to a large area of chain effect, even causes the overall instability of the excavation. For example, the excavation collapse accident of Xianghu Station of Hangzhou Subway in Hangzhou, China in 2008 (Gong and Zhang 2012; Tan Y et al. 2018) [1]-[2] and the Nicoll Subway collapse accident in Singapore in 2004 (Salih et al. 2018; Zhang et al. 2018) [3]-[4]. These two accidents have the same characteristics: the failure both started from the failure of a single horizontal strut, then affected adjacent horizontal struts, and eventually leaded to the instability of the whole supporting structure.

Redundancy is regarded as the ability of structure to resist continuous collapse in the field of civil engineering, and was mainly used to calculate the stability of truss

\footnotetext{
${ }^{1}$ Linfeng Wang, School of Civil Engineering, Chongqing University, Chongqing 400045, P.R. China; E-mail: 476964211@qq.com.
} 
structures and bridge structures in the early time (Frangopol and Curley 1987; Paliou et al. 1990; Marjanishvili 2004; Starossek 2007) [5]-[8]. In the 1980s, Osterberg (1989) [9] proposed to introduce the concept of redundancy into geotechnical engineering to prevent the failure of underground structures in some projects. Zheng et al. (2011) [10] first proposed the concept of redundancy of excavation engineering and the framework of redundancy design method. Since then, many scholars have promoted the application of redundancy theory in the stability analysis of excavation supporting structures from the aspects of theoretical calculation, numerical simulation and model test. Zheng et al. (2021) [11] carried out the failure model test of retaining walls, horizontal struts and anchors, and discussed the load transfer mechanism and failure mode of the overall failure caused by local failure of these supporting structures. Choosrithong and Schweiger (2020) [12] analyzed the influence of the failure of a single strut on the overall stability of a soft clay excavation by numerical simulation. Liu et al. (2017) [13] discussed the optimal distribution form of anchors under the condition of collaborative deformation by calculating the collaborative deformation redundancy ratio of joints between struts and anchors. Cheng et al. (2017a; 2017b) [14]-[15] obtained the occurrence mechanism and evolution mechanism of partial collapse (sudden failure of some retaining piles) and progressive collapse through model test and finite difference calculation software.

Since the concept has not been applied for a long time in excavation engineering, there are few studies on the redundancy of the supporting structures in excavations. In addition, most of the existing researches only consider the failure of a single strut, ignoring the failure of several struts in a certain range, which is more destructive. At the same time, due to the significant spatial effect of the excavation, the location and position of the failure structure will also cause differences in the overall stability.

In view of this, based on an excavation of an expressway in Guangzhou, China, and based on the redundancy theory, the numerical calculation model of the diaphragm walls + horizontal struts was established by $\mathrm{Flac}^{3 \mathrm{D}} 5.0$, and the reliability of the supporting structure after local failure of the struts was discussed. The conclusion has certain theoretical and practical significance for the application of redundancy theory in excavation.

\section{Expression of Redundancy Theory}

\subsection{Expression of Redundancy Theory Based on Strength}

Frangopol and Curley (1987) [5] believes that the redundancy characteristics of the component should be evaluated from the perspective of the performance of the components and the overall bearing capacity of the structure. Accordingly, the calculation formula of structural member redundancy parameters is proposed as follows:

$$
R=\frac{L_{\text {int act }}}{L_{\text {int act }}-L_{\text {damage }}}
$$

where $L_{\text {intact }}$ is the ultimate bearing capacity of the initial structure, $L_{\text {damage }}$ is the ultimate bearing capacity of the damaged structure. 
Jiang et al. (2015) [16] rewrote the redundancy calculation formula based on structural component strength proposed by Frangopol and Curley (1987) [5] and defined it as:

$$
R=\frac{N_{\text {intact }}}{N_{\text {damage }}-N_{\text {intact }}}
$$

where $N_{\text {intact }}$ is the maximum internal force value of the original structure, and $N_{\text {damage }}$ is the maximum internal force value of the damaged structure.

\subsection{Expression of Redundancy Theory Based on Deformation}

In excavation engineering, not only the bearing capacity of the supporting structure should be considered, but also the deformation of supporting structure. Jiang et al. (2015) [16] obtained the redundancy calculation Formula (Eq. (3)) based on deformation by referring to Eq. (2):

$$
R=\frac{S_{\text {intact }}}{S_{\text {damage }}-S_{\text {intact }}}
$$

where $S_{\text {intact }}$ is the maximum deformation value of the original structure, and $S_{\text {damage }}$ is the maximum deformation value of the damaged structure.

\section{Project Background}

The excavation of the north section of the second expressway of Guangzhou New Baiyun International Airport is $3012.0 \mathrm{~m}$ in length, $40.0-41.0 \mathrm{~m}$ in width, and 3.1 $16.2 \mathrm{~m}$ in depth. $\mathrm{K} 7+900-\mathrm{K} 8+020$ is chosen as an example to be analyzed, and the excavation is $120.0 \mathrm{~m}$ long, $40.0 \mathrm{~m}$ wide and $14.0 \mathrm{~m}$ deep. $1.0 \mathrm{~m}$ thick diaphragm walls and three struts are chosen to support the excavation. The depth of the diaphragm wall is $8.0 \mathrm{~m}$ and is embedded in the moderate-weathered limestone. The first struts are 0.6 $\mathrm{m} \times 0.8 \mathrm{~m}$ concrete struts with a horizontal spacing of $12.0 \mathrm{~m}$. The second and third struts are $\varphi 609 \times 16 \mathrm{~mm}$ steel pipes. The vertical distance of the struts is $4.0 \mathrm{~m}$ and the horizontal spacing is $4.0 \mathrm{~m}$. The excavation profile is shown in figure 1 .

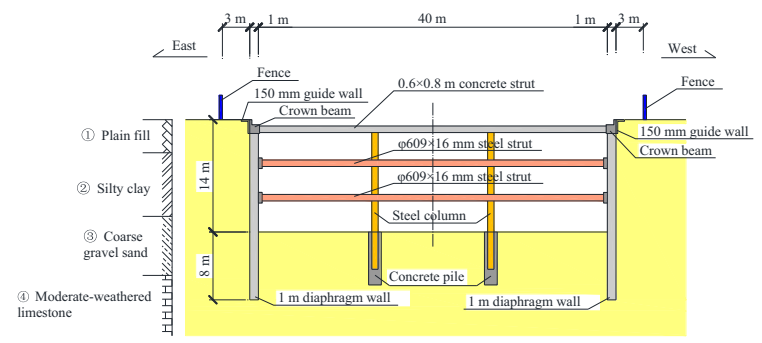

Figure 1. Cross-sectional of the supporting structures. 


\section{Numerical simulation}

\subsection{Constitutive Model and Parameters}

The Mohr-Coulomb constitutive model is used to simulate the soil and rock around the excavation, and the parameters are shown in table 1. Solid elements are used to simulate the diaphragm walls and crown beams, and the ideal elastic constitutive model is used by ignoring the plastic state. Concrete struts and steel struts are simulated by beam element, while steel columns and erect column piles are simulated by pile element. The elastic modulus of concrete members is converted by considering its reinforcement ratio. Specific parameters of supporting structure are shown in table 2 .

Table 1. Physical and mechanical parameters of rock and soil.

\begin{tabular}{|c|c|c|c|c|c|c|}
\hline Soil & $\begin{array}{l}\text { Thicknes } \\
\mathrm{s} \\
/ \mathrm{m}\end{array}$ & $\begin{array}{l}\text { Elastic } \\
\text { modulus } \\
E / \mathrm{MPa}\end{array}$ & $\begin{array}{l}\text { Density } \\
\rho / \\
\left(\mathrm{kg} / \mathrm{m}^{3}\right)\end{array}$ & $\begin{array}{l}\text { Cohesion } \\
c / \mathrm{kPa}\end{array}$ & $\begin{array}{l}\text { Friction } \\
\text { angle } \\
\varphi /\left(^{\circ}\right)\end{array}$ & $\begin{array}{l}\text { Poisson's } \\
\text { ratio } v\end{array}$ \\
\hline Plain fill & 4 & 6.0 & 1850 & 20.0 & 9 & 0.35 \\
\hline Silty clay & 8 & 10.0 & 2000 & 21.0 & 11 & 0.30 \\
\hline Coarse gravel sand & 7 & 33.0 & 1870 & 30.0 & 38 & 0.23 \\
\hline $\begin{array}{l}\text { Moderate- } \\
\text { weathered limestone }\end{array}$ & - & 15000.0 & 2300 & 45.0 & 35 & 0.21 \\
\hline
\end{tabular}

Table 2. Physical and mechanical parameters of supporting structures.

\begin{tabular}{llllll}
\hline Name & Material & Size $/ \mathrm{mm}$ & $\begin{array}{l}\text { Density } \\
\rho /\left(\mathrm{kg} / \mathrm{m}^{3}\right)\end{array}$ & $\begin{array}{l}\text { Elastic modulus } \\
E / \mathrm{MPa}\end{array}$ & $\begin{array}{l}\text { Poisson's ratio } \\
v\end{array}$ \\
\hline Diaphragm wall & C30 RC & 1000 & 2500 & 32.9 & 0.2 \\
Crown beam & C30 RC & $1200 \times 1000$ & 2500 & 35.8 & 0.2 \\
Concrete strut & C30 RC & $600 \times 800$ & 2500 & 33.4 & 0.2 \\
Steel strut & Steel & $\varphi 609 \times 16$ & 7800 & 200 & 0.3 \\
Steel column & Steel & $550 \times 550$ & 7800 & 200 & 0.3 \\
Concrete pile & C30 RC & d1000 & 2500 & 31.7 & 0.2 \\
\hline
\end{tabular}

Set contact between the soil and the underground structures to accurately reflect the interaction between the soil and the retaining structures. The parameters for the final determination of the contact surface are shown in table 3.

Table 3. Parameter of contact surface.

\begin{tabular}{lllll}
\hline Location & $\begin{array}{l}\text { Normal stiffness } K_{n} / \\
\mathrm{GPa} / \mathrm{m}\end{array}$ & $\begin{array}{l}\text { Shear stiffness } K_{s} / \mathrm{GPa} \\
/ \mathrm{m}\end{array}$ & $\begin{array}{l}\text { Cohesion } c / \\
\mathrm{kPa}\end{array}$ & $\begin{array}{l}\text { Friction angle } \\
\varphi /{ }^{\circ}\end{array}$ \\
\hline $\begin{array}{l}\text { Bottom of the } \\
\text { diaphragm wall }\end{array}$ & 112 & 112 & 35 & 28 \\
$\begin{array}{l}\text { Contact with } \\
\text { limestone }\end{array}$ & 112 & 112 & 35 & 28 \\
$\begin{array}{l}\text { Contact with sand } \\
\text { Contact with clay }\end{array}$ & 0.15 & 0.15 & 24 & 30 \\
$\begin{array}{l}\text { Contact with fill } \\
\text { Crown beam }\end{array}$ & 0.09 & 0.09 & 16 & 8 \\
\end{tabular}

\subsection{Simulation Model and Process}

Numerical analyses are carried out using the 3D finite difference software Flac ${ }^{3 \mathrm{D}} 5.0$. The excavation is $120 \mathrm{~m}$ long, $40 \mathrm{~m}$ wide and $14 \mathrm{~m}$ deep. Considering the influence range of the excavation, the side of the model is $50 \mathrm{~m}$ from the pit. In order to facilitate 
modeling and analysis, it is assumed that all soil layers are evenly distributed in horizontal layers, and the vertical boundary of the model is set at $45 \mathrm{~m}$. The final size of the model is $220 \mathrm{~m} \times 140 \mathrm{~m} \times 45 \mathrm{~m}$. The bottom boundary of the model was fixed totally while the top surface was left free. The lateral sides of the model were fixed in the horizontal direction while vertical movement was allowed. The established numerical calculation model consists of 68518 nodes and 94582 units. Figure 2 shows the numerical model, including necessary dimensions and instructions.

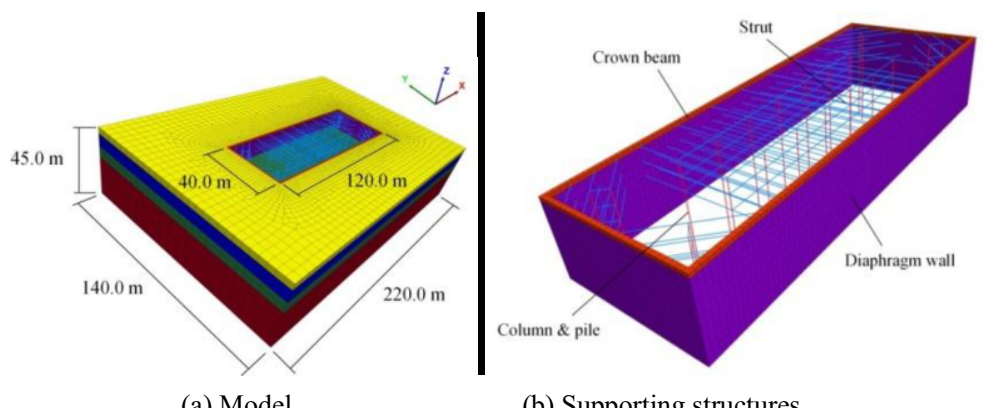

(a) Model.

(b) Supporting structures.

Figure 2. Numerical calculation model.

The simulation is divided into the following steps according to the actual situation:

(1) Establishing initial model according to the parameters of soil layers and supporting structure. Clearing displacement to reach the initial stress balance state before excavation;

(2) Constructing supporting structures, including diaphragm walls, uplift piles, steel erect columns;

(3) Excavating to $1.0 \mathrm{~m}$ depth, constructing crown beam and installing the first concrete struts in $0.5 \mathrm{~m}$ depth;

(4) Excavating to $5.0 \mathrm{~m}$ depth and install the second steel struts in $4.5 \mathrm{~m}$ depth;

(5) Excavating to $9.0 \mathrm{~m}$ depth and install the third steel struts in $8.5 \mathrm{~m}$ depth;

(6) Excavating to bottom of the excavation in $14.0 \mathrm{~m}$ depth.

\section{Reliability Analysis of Horizontal Struts}

\subsection{Failure of a Single Strut}

To simulate the situation of failure of a single strut, the left half of the concrete struts is numbered according to the symmetry of the model (figure 3), and struts (1) - (7) are deleted, respectively, to study the influence of the failure of a single strut at different positions on the supporting system.

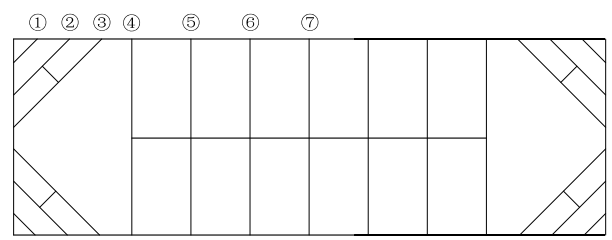

Figure 3. Number of the struts. 
The axial forces of each strut in the first row when a single strut fails are shown in figure 4. Due to the spatial effect, the axial forces of horizontal struts along the length direction of the excavation are basically small at the two ends and large in the middle. The axial forces of the two ends are between $850-1050 \mathrm{kN}$, and that in the middle are between $1250-1350 \mathrm{kN}$. The failure of a single strut mainly affects the two adjacent struts, and the maximum increase of the axial force caused by failure is within $20 \%$.

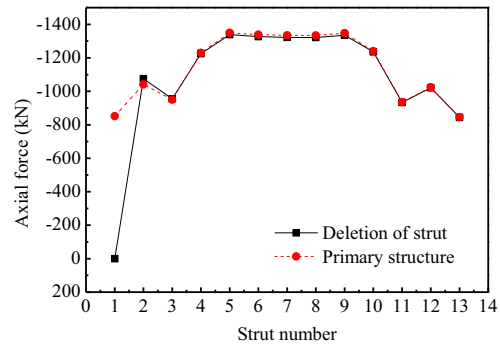

(a) Failure of strut (1).

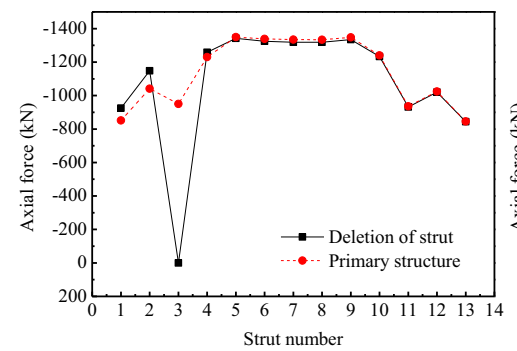

(c) Failure of strut (3).

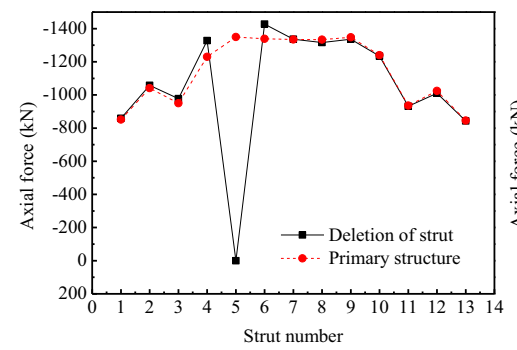

(e) Failure of strut (5).

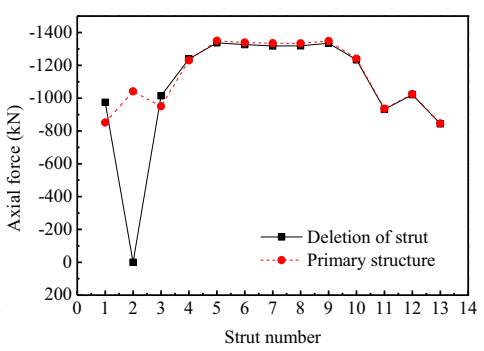

(b) Failure of strut (2).

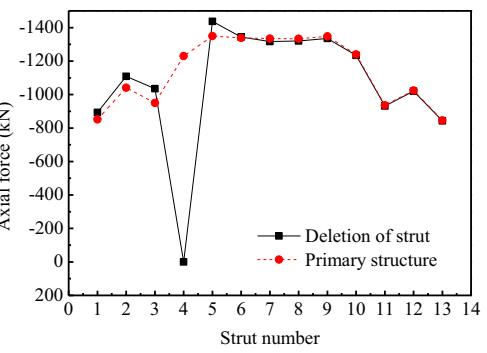

(d) Failure of strut (4).

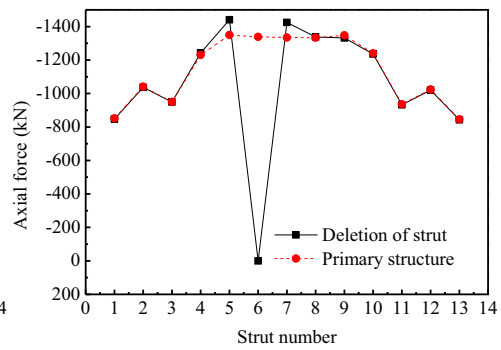

(f) Failure of strut (6).

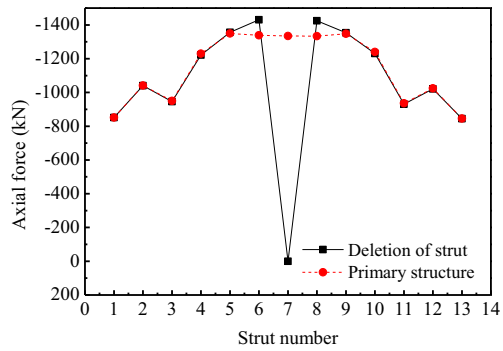

(g) Failure of strut (7).

Figure 4. The axial force of each strut in the first struts structure after failure of one strut. 
The strength redundancy of each strut is calculated according to Eq. (2), and is listed in table 4. It can be seen that the strength redundancy of each strut is large, indicating that the failure of a single strut has little influence on the whole system. The strength redundancy of strut (1) and strut (3) is negative. It is mainly because the failure of a corner strut only affects adjacent corner struts, of which the axial forces are small and will not exceed that of the transverse struts. On the contrary, due to the further performance of the remained corner struts, the axial forces on the transverse struts will be reduced, leading to more uniform load on the whole system. The strength redundancy of strut (6) is the smallest, which is 14.85 , indicating that strut (6) is the most important in the first row.

Table 4. Strength redundancy of each concrete strut.

\begin{tabular}{lll}
\hline Working condition & Maximum axial force/ kN & Strength redundancy \\
\hline Primary structure & 1349.69 & - \\
Failure of strut (1) & 1338.34 & -118.92 \\
Failure of strut (2) & 1336.86 & -114.09 \\
Failure of strut (3) & 1342.3 & -182.64 \\
Failure of strut (4) & 1437.13 & 15.44 \\
Failure of strut (5) & 1427.53 & 17.34 \\
Failure of strut (6) & 1440.58 & 14.85 \\
Failure of strut (7) & 1430.71 & 16.66 \\
\hline
\end{tabular}

\subsection{Continuous Failure of Multiple Struts}

In practical engineering, most accidents are caused by continuous collapse. As can be seen from the above, when a horizontal strut fails, the axial force on the adjacent struts will increase, which may lead to continuous failure due to exceeding of the bearing capacity. Therefore, further studies are carried out based on the deletion of the single strut mentioned above. Strut (2) is deleted after strut (1), and the next one is strut (3), and so on, and finally strut (1) - (7) will be all deleted. The Y-displacement of the soil around the excavation is shown in figure 5.

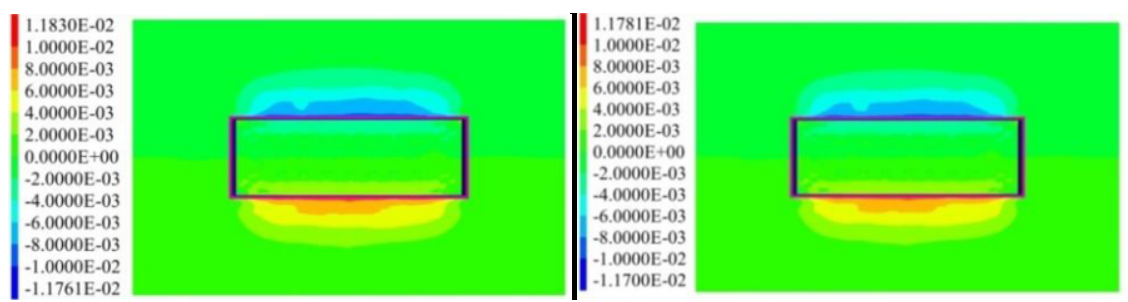

(a) Primary structure.

(b) Failure of strut (1).

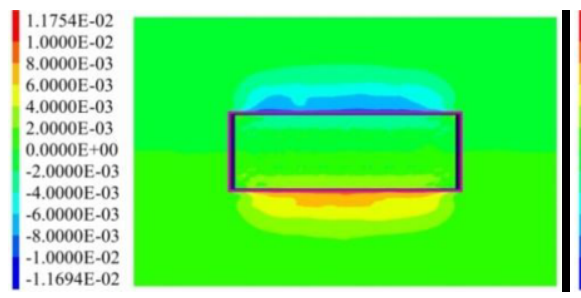

(c) Failure of strut (1) - (2).

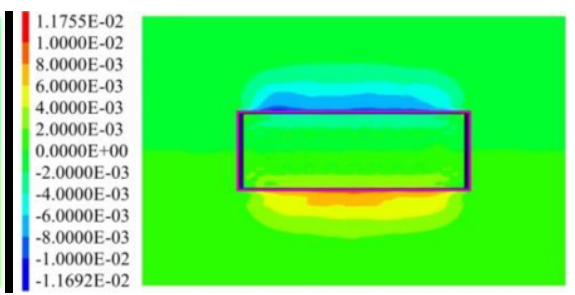

(d) Failure of strut (1) - (3). 


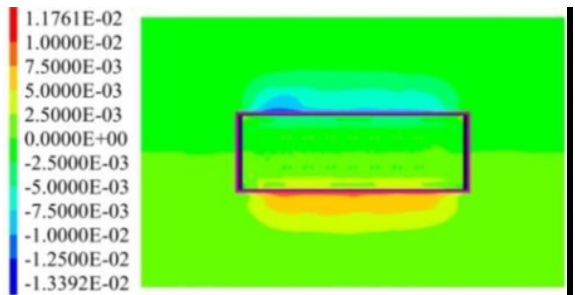

(e) Failure of strut (1) - (4).

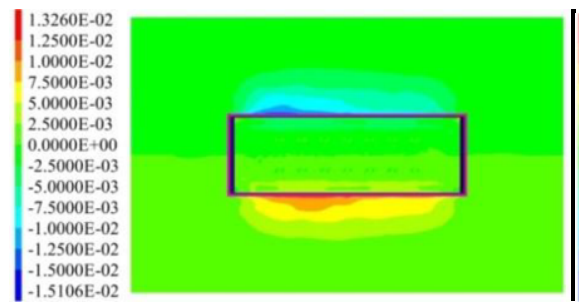

(g) Failure of strut (1) - (6).

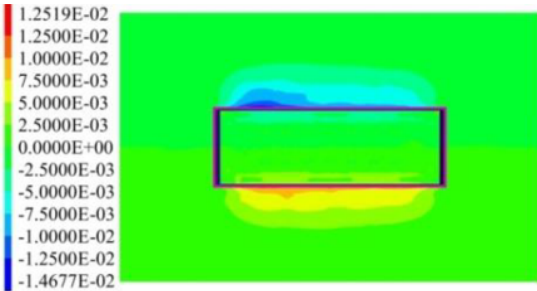

(f) Failure of strut (1) - (5).

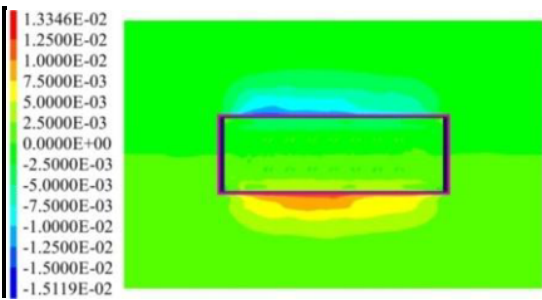

(h) Failure of strut (1) - (7).

Figure 5. Y-displacement of surrounding soil after failure of several struts (unit: $\mathrm{m}$ ).

With the continuous failure of struts, the displacement of the surrounding soil adjacent to the failed struts increases successively. The failure of corner struts has little effect on the maximum lateral deformation, while the failure of transverse struts will significantly increase the deformation from $11.76 \mathrm{~mm}$ to $15.12 \mathrm{~mm}$. According to Eq. (3), the value of deformation redundancy of multiple struts is calculated in table 5. In general, with the continuous failure of struts, the deformation redundancy becomes smaller. When the corner struts are deleted, the deformation redundancy is negative. With the failure of transverse struts, the redundancy decreases significantly, and the value is only 3.50 when strut (1) - (7) all fail.

Table 5. Deformation redundancy of multiple struts.

\begin{tabular}{lll}
\hline Working condition & Maximum deformation/ $\mathrm{mm}$ & Deformation redundancy \\
\hline Primary structure & 11.76 & - \\
Failure of strut (1) & 11.70 & -196.00 \\
Failure of strut (1) - (2) & 11.69 & -168.00 \\
Failure of strut (1) - (3) & 11.69 & -168.00 \\
Failure of strut (1) - (4) & 13.39 & 7.21 \\
Failure of strut (1) - (5) & 14.68 & 4.03 \\
Failure of strut (1) - (6) & 15.11 & 3.51 \\
Failure of strut (1) - (7) & 15.12 & 3.50 \\
\hline
\end{tabular}

\subsection{Failure of One Row of the Struts}

The situations of the failure of one row of the struts are discussed in this section. Three working conditions are divided: working condition 1: failure of the first row; working condition 2: failure of the second row; working condition 3: failure of the third row. Lateral movements of the diaphragm wall along depth under different working conditions are shown in figure 6.

When the first row fails (working condition 1), the top of the walls moves towards the excavation and the maximum lateral movement exceeds $15.0 \mathrm{~mm}$. After the failure 
of the second row (working condition 2), the lateral movement becomes larger with the value of $17.6 \mathrm{~mm}$. After the failure of the third row (working condition 3), the lateral movement is the smallest, and the curve is more like that of the primary structure. It is mainly because the third row is close to the base, the soil of the passive zone restrains the lateral movement of the diaphragm walls to a certain extent. Besides, the strength of the soil near the base is higher than that of the soft clay in the upper part.

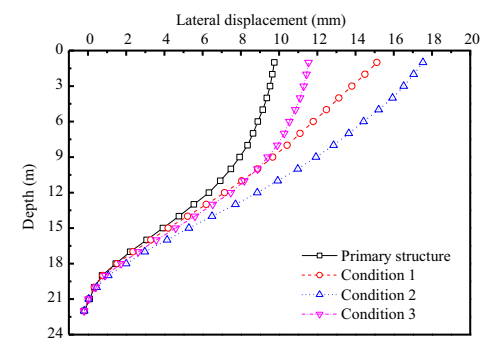

Figure 6. Lateral deformation of diaphragm walls under different working conditions (A positive value indicates that the displacement is toward the interior of the pit).

Figure 7 (a) - Figure 7 (c) show the axial force of each strut after failure of the first, second and third row of the struts, respectively. After the failure of the first row, the axial force of the nearest second row increases by about $400 \mathrm{kN}$, while that of the third row increased by about $200 \mathrm{kN}$ due to its further distance. When the second row fails, the axial force of the first row will increases significantly, and the maximum axial force increases from more than $1200 \mathrm{kN}$ to nearly $2200 \mathrm{kN}$. The axial force of the third row increases from about $450 \mathrm{kN}$ to more than $800 \mathrm{kN}$. After the failure of the third row, the axial force of the first and second row increases by about $200 \mathrm{kN}$, which is more smaller than failure of the first and second row.

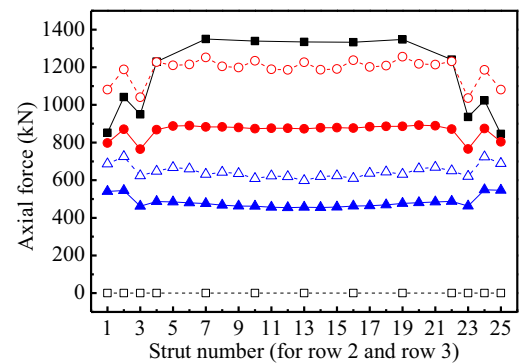

(a) Failure of row 1.

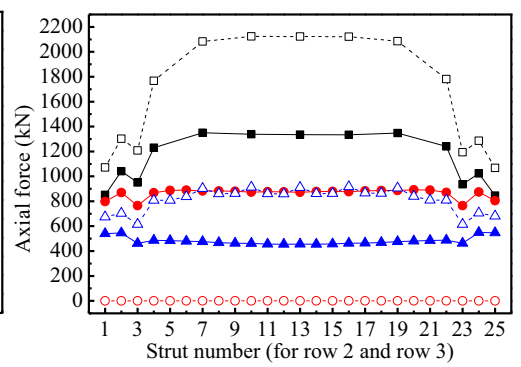

(b) Failure of row 2.

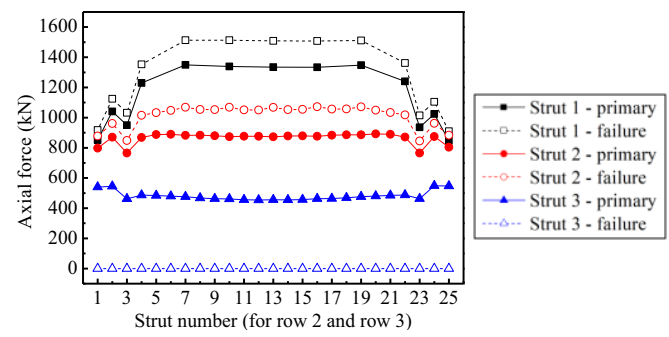

(c) Failure of row 3.

Figure 7. Axial force distribution of each strut after failure of a row of struts ("Strut number" in $\mathrm{x}$-axis refers to struts of row 2 and row 3 , and struts of row 1 are corresponding according to figure 7). 
The strength redundancy and the deformation redundancies of each row of the struts are calculated by Eq. (1) and Eq. (2), respectively, as listed in table 6. It can be seen that the deformation redundancy of the second row of the struts is the smallest, indicating that the failure of this row will seriously affect the whole structure. While that of the third row is the biggest and the failure has little effect on the whole structure. The importance of the second row can also be proved by its smallest strength redundancy. Different from the conclusion obtained by deformation redundancy, the strength redundancy of the first row of the strut is negative. This is mainly because the maximum axial force is on the first row. Even if the failure of the first row leads to the increase of the axial force of the second row, the maximum does not exceed that of the first row in the initial structure. In this case, the deformation redundancy index should be used to control the structure safety. The strength redundancy and the deformation redundancy of the third row are both large, indicating that the third support plays a small role in the whole structure. Combined with the actual axial force level of the third row, it can be optimized according to the actual situation.

Table 6. Strength redundancy and deformation redundancy of each row of struts.

\begin{tabular}{lllll}
\hline Working condition & $\begin{array}{l}\text { Maximum } \\
\text { deformation/mm }\end{array}$ & $\begin{array}{l}\text { Deformation } \\
\text { redundancy }\end{array}$ & $\begin{array}{l}\text { Maximum axial } \\
\text { force/ } \mathrm{kN}\end{array}$ & $\begin{array}{l}\text { Strength } \\
\text { redundancy }\end{array}$ \\
\hline Primary structure & 9.75 & - & 1349.69 & - \\
Failure of the first row & 15.12 & 1.82 & 1256.2 & -14.44 \\
Failure of the second row & 17.53 & 1.25 & 2124.35 & 1.74 \\
Failure of the third row & 11.54 & 5.45 & 1512.87 & 8.27 \\
\hline
\end{tabular}

\section{Conclusion}

The numerical calculation model of the deep excavation was established by Flac ${ }^{3 \mathrm{D}} 5.0$, and the influence of local failure of horizontal struts on the stability of the whole supporting structures was discussed by deleting bars. Based on the redundancy theory, the reliability of the supporting structures was analyzed, and the following conclusions were obtained:

(1) Failure of a single strut mainly affects the two adjacent struts, making the axial forces increasing within $20 \%$. The strength redundancy of the strut (6) (close to the middle of the excavation) is the smallest and the value is 14.85 , indicating that it is the most important one in the first row of the struts.

(2) After continuous failure of the struts, the soil displacement adjacent to the failure strut increases successively. Different from the failure of the corner struts, the failure of the transverse struts will significantly increase the lateral movement of the excavation, as well as the influence range. The more failed struts are, the smaller the deformation redundancy is, and the redundancy is only 3.50 when strut (1) - (7) are all failed (half of the struts).

(3) The lateral movement of the diaphragm walls caused by the failure of the second row of the struts is the most significant, and those caused by the failure of the third row of the struts is the least significant. After the failure of the second row, the axial forces of the first and the third row of the struts increase significantly, while those of the first and second row of the struts do not increase significantly after the failure of the third row. The second row of the struts has the least strength redundancy and deformation redundancy. The strength redundancy and the deformation redundancy of 
the third row of the struts are both large, indicating a small role in the whole supporting structure. Since the strength redundancy of the first row of the struts is negative, it should be controlled by the deformation redundancy index.

\section{Acknowledgements}

The study is supported by Graduate Scientific Research and Innovation Foundation of Chongqing, China (Grant No. CYB20031).

\section{References}

[1] Gong XN, Zhang XC. Excavation collapse of Hangzhou subway station in soft clay and numerical investigation based on orthogonal experiment method. Journal of Zhejiang University-Science A. 2012 Oct; 13(10): 760-767.

[2] Tan Y, Jiang WZ, Luo WJ, Lu Y, Xu CJ. Longitudinal Sliding Event during Excavation of Feng-Qi Station of Hangzhou Metro Line 1: Postfailure Investigation. Journal of Performance of Constructed Facilities. 2018 Aug; 32(4): 04018039.

[3] Salih SH, Hassan MM, Shian J, Hossain Z. A Revisit to Nicoll Highway Excavation in Singapore. International Journal of Geomate. 2018 Feb; 14(42): 90-96.

[4] Zhang WG, Zhang RH, Fu YR, Goh ATC, Zhang F. 2D and 3D numerical analysis on strut responses due to one-strut failure. Geomechanics and Engineering. 2018 Jul; 15(4): 965-972.

[5] Frangopol DM, Curley JP. Effects of damage and redundancy on structural reliability. Journal of Structural Engineering-ASCE. 1987 Jul; 113(7): 1533-1549.

[6] Paliou C, Shinozuka M, Chen Y. Reliability and redundancy of offshore structures. Journal of Engineering Mechanics. , 1990 Feb; 116(2): 359-378.

[7] Marjanishvili SM. Progressive analysis procedure for progressive collapse. Journal of Performance of Constructed Facilities. 2004 May; 18(2): 79-85.

[8] Starossek U. Typology of progressive collase. Engineering Structure. 2007 Sep; 29: 2302-2307.

[9] Osterberg JO. Necessary redundancy in geotechnical engineering. Journal of Geotechnical EngineeringASCE. 1989 Nov; 115(11): 1513-1531.

[10] Zheng G, Cheng XS, Diao Y, Wang HX. Concept and design methodology of redundancy in braced excavations. Geotechnical Engineering. 2011 Sep; 42(3): 13-21.

[11] Zheng G, Lei YW, Cheng X, Li XY, Wang RZ. Experimental study on progressive collapse mechanism in braced and tied-back retaining systems of deep excavations. Canadian Geotechnical Journal. 2021 Apr; 58(4): 540-564.

[12] Choosrithong K, Schweiger HF. Numerical Investigation of Sequential Strut Failure on Performance of Deep Excavations in Soft Soil. International Journal of Geomechanics. 2020 Jun; 20(6): 04020063.

[13] Liu JY, Li B, Liu Y, Cai SB. Design method of redundancy of brace-anchor sharing supporting based on cooperative deformation. IOP Conference Series: Earth and Environmental Science. 2017 Jul; 94 : 012202 .

[14] Cheng XS, Zheng G, Diao Y, Huang TM, Deng CH, Nie DQ, Lei YW. Experimental study of the progressive collapse mechanism of excavations retained by cantilever piles. Canadian Geotechnical Journal. 2017 Apr; 54(4): 574-587.

[15] Cheng XS, Zheng G, Diao Y, Huang TM, Deng CH, Lei YW, Zhou HZ. Study of the progressive collapse mechanism of excavations retained by cantilever contiguous piles. Engineering Failure Analysis. 2017 Jan; 71: 72-89.

[16] Jiang J, Gu QY, Hu H, Yu MX, Ma SK. Study of redundancy of double-row steel sheet piles cofferdam. Rock and Soil Mechanics. 2015 Jul; 36(S1): 518-522. (in Chinese) 